Article

\title{
Urban Physical Environments and the Duration of High Air Temperature: Focusing on Solar Radiation Trapping Effects
}

\author{
Yeri Choi, Sugie Lee * and Hyunbin Moon \\ Department of Urban Planning and Engineering, Hanyang University, 222 Wangsimni-ro, Seongdong-gu, \\ Seoul 04763, Korea; yeri0610@hanyang.ac.kr (Y.C.); moonwk1713@hanyang.ac.kr (H.M.) \\ * Correspondence: sugielee@hanyang.ac.kr
}

Received: 15 November 2018; Accepted: 14 December 2018; Published: 18 December 2018

\begin{abstract}
Urban heat island effects, which are the phenomenon wherein higher ambient air temperatures are measured in cities than in rural areas, have worsened urban thermal environments over the past decades. This study aims to analyze the effects of urban physical environments on the duration of high air temperature, using climate data collected from 217 Automatic Weather Stations in Seoul, Korea. In order to specify radiation trapping effects, interaction effects between sky view factors (SVF) and albedo values were analyzed using multiple regression analysis. The results indicate that increases in commercial and traffic areas lead to longer durations of high air temperature and that high urban porosity shortens the duration of high air temperature by improving urban ventilation. This study also indicates that the duration of high air temperature has a negative association with SVF; however, an analysis of interaction effects indicates that high-albedo materials diminish the positive effects of high SVF largely because of radiation trapping effects. These findings suggest that urban ventilation paths, high SVF, and materials with an appropriate albedo value play important roles in improving thermal comfort conditions, such as the duration of high air temperature.
\end{abstract}

Keywords: air temperature; physical environment; solar radiation trapping effect; urban geometry; urban heat island effects

\section{Introduction}

\subsection{Background}

With the current climate change and global warming trends, average air temperatures are rising worldwide; this phenomenon has had a particularly critical impact on thermal environments in densely built-up urban areas with impervious surfaces, causing Urban Heat Island (UHI) effects. In relation to this, heat waves in cities have become a very serious issue in terms of both their intensity and frequency. Furthermore, UHI effects have perilous repercussions on people's health (i.e., excess heat-related mortality and morbidity rates) and labor productivity [1,2].

Two increasing public demands in Seoul, Republic of Korea, are to mitigate UHI effects and to ameliorate thermal comfort in outdoor areas. According to a report released in 2010, the annual mean temperature in Seoul from 1970 to 2009, and the number of tropical days, in which daily maximum temperatures exceed $30{ }^{\circ} \mathrm{C}$, have continuously increased [3]. UHI effects have become a threat to urban populations in the Seoul area as well; thus, the Seoul Metropolitan Government has devised and adopted various UHI mitigation strategies. The augmentation of vegetated areas and open water surfaces, the application of cool paving materials, and the creation of urban wind corridors for ventilation have been suggested as possible mitigation strategies to lower air temperatures in the city. 


\subsection{Aims and Needs for the Present Study}

The present study investigated the effects of urban elements on urban thermal environments. Further, our findings suggest policy implications for improving pedestrian thermal comfort. Most of the previous studies on the urban thermal environment have focused mainly on air or surface temperatures, and their results were obtained by using numerical simulations due to the lack of available data. However, the present study adopted a new variable to explain the extent of UHI effects and the duration of high air temperatures. Furthermore, we empirically analyzed the ways in which urban physical environments impact the duration of high air temperature, using climate data collected from 217 Automatic Weather Stations (AWSs) located around Seoul. Regarding the data we have used, there is a strong need for higher resolution climate data since it delivers more reliable results [4]. Therefore, more accurate results were yielded in the current study, in that relatively detailed climate data in the study area were utilized.

The aim of the current study was to examine the relationships between urban physical environments and the duration of high air temperature, and to present implications for ameliorating urban thermal environments.

\section{Literature Review}

A number of studies have been published on the physical components of urbanized areas, ranging from building density to surface characteristics, and their impacts on UHI effects. Therefore, after reviewing previous studies, morphological characteristics of cities, which are reported to affect urban thermal environments, were selected and applied to the present study.

\subsection{Land Use and Surface Characteristics}

To examine the relationships between physical properties in cities and UHI effects, previous researchers have analyzed the impacts of urban surface characteristics (e.g., the fraction of green spaces and water bodies, impervious surface coverage, albedo values, and other features) on temperature.

The positive effects of urban vegetation on outdoor thermal environments are commonly reported in many studies. The surface temperature of vegetated areas is significantly lower compared to that of impervious urban surfaces; moreover, urban vegetation has mitigating effects on air temperature as well [5-13]. Taleghani et al. (2014) conducted field measurements in order to explore the impacts of vegetation in summer and winter, and their results indicated that the augmentation of vegetation might be an effective heat mitigation strategy in both seasons. This study showed that the air temperature measured in a vegetated courtyard was at most $4.7^{\circ} \mathrm{C}$ lower than that of bare soil in summer, and that a green roof had higher air temperatures compared to a white gravel roof in winter [10]. Moreover, Sahana et al. (2018) analyzed the relation between land transformation and land surface temperatures in Mumbai city, India, using Landsat images taken in 1990, 2000 and 2015. Their results showed that the land-cover change from vegetation and agricultural land to built-up urban areas was one of the main causes of increased land surface temperatures in the study area [12]. Further studies on the role of green spaces found that their effects varied in accordance with the amount and arrangement pattern of vegetation $[6,8,9]$. A study by Konarska et al. (2016) explored thermal environments that focused on cooling rates; the results indicated that vegetation plays an important role in enhancing cooling rates [11].

A number of studies have analyzed the impact of water bodies on thermal environments. Most of the previous studies yielded consistent results indicating that open water spaces help to mitigate UHI effects by lowering air temperatures; the rationale behind this is the evaporation of water [14-16]. With regard to the positive impacts of water bodies in mitigating UHI effects in surrounding areas, a study by Syafii et al. (2017) went one step further by identifying various effects of ponds in different configurations. Ponds with a larger surface area tend to have a more significant cooling effect. Moreover, this study indicated that water bodies positively affect outdoor pedestrian thermal comfort 
and the Physiological Equivalent Temperature (PET) [16]. On the other hand, the results of a study by Steeneveld et al. (2014) showed that urban lakes led to deterioration of UHI effects. The researchers added that this phenomenon was caused by the relatively high heat capacity of water; in other words, high air temperatures tended to remain longer around water bodies due to distinctive characteristics of water, which hamper rapid cooling after sunset [17].

Similarly, Mackey et al. (2012) monitored UHI effects in Chicago and explored the link between urban surface characteristics, including albedo values and Normalized Difference Vegetation Index (NDVI), and surface temperatures from Landsat images. The study found that reflective strategies to increase albedo values and NDVI might be effective at lowering surface temperatures and cooling the city [18]. A study by Xiao et al. (2007) carried out empirical research in order to explore variations of land surface temperatures across various land-use types and found a strong positive relationship between surface temperatures and the fraction of impervious areas [19].

The impact of land-use patterns on air temperatures has also been reported in previous studies, since surface characteristics vary depending on the land use type (e.g., a dearth of vegetation in commercial areas or low albedo values in industrial areas) [20,21].

\subsection{Three-Dimensional Characteristics within the Urban Canyon}

Early studies mainly concentrated on urban surface characteristics when explaining the influences of urban elements on thermal environments. Three-dimensional (3D) characteristics of urban street morphologies have been adopted only in relatively recent research, even though the concept of street/urban canyon geometries' effects on city microclimates has been demonstrated for decades [22].

The effect of street canyon geometry can be easily understood as the impacts of the building and street configurations on outdoor thermal environments. These configurations greatly affect thermal environments in urban canyons, whether they improve or limit ventilation performance, reflection of incident solar radiation, shading effects, and other features [22-25]. The lack of open spaces in a densely built-up area impedes the release of heated air into the atmosphere, and tall buildings diminish wind speeds and hamper the cooling effects of wind flow. In addition, building envelopes with high heat storage capacities contribute to high ambient air temperatures and, eventually, the heated air is trapped within the urban canyon.

A number of previous studies have addressed solar radiation trapping (Figure 1), referring to the phenomenon wherein incident solar radiation continues to bounce off of urban surfaces (i.e., building facades and road surfaces) within the canyon [26-28]. To have a better understanding of urban thermal environments, it is necessary to carefully consider the effects of solar radiation trapping; in order to do this, numerical simulations were applied as a research methodology in some of the previous studies on this subject [28-30].

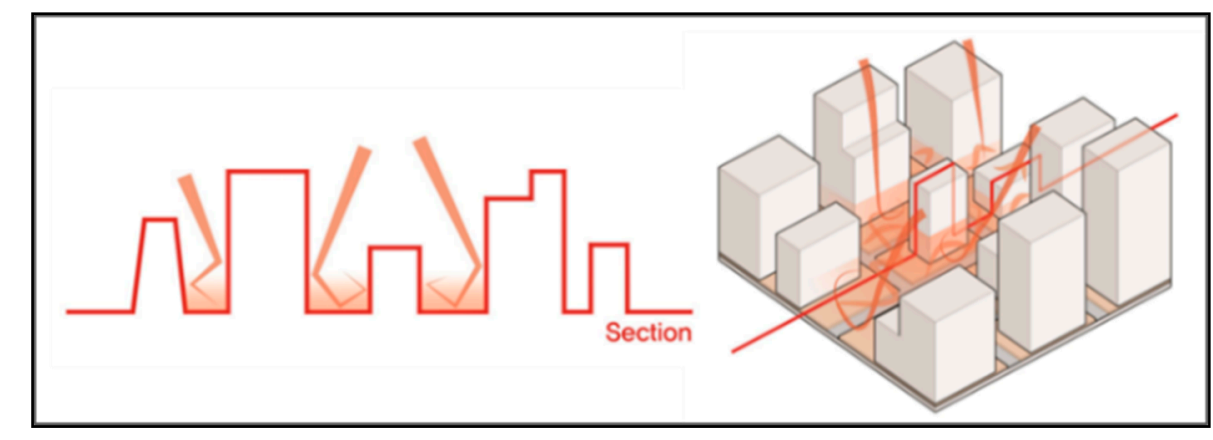

Figure 1. Illustration of solar radiation trapping effects.

One of the primary parameters that determine the characteristics of street canyons is the Sky View Factor (SVF). The SVF describes the fraction of sky visible at a given point; SVF values range from 0 to 1 , and higher values indicate greater canopy openness (Figure 2). Therefore, heated air during the 
daytime is less trapped and more effectively emitted to the atmosphere within an urban canopy with a high SVF. Most prior studies found that the SVF is one of the major factors that determine urban thermal environments, and reported that, in terms of air temperatures and pedestrian thermal comfort, streets with high SVF values had relatively more desirable thermal environments than streets with low SVF values [31-33].

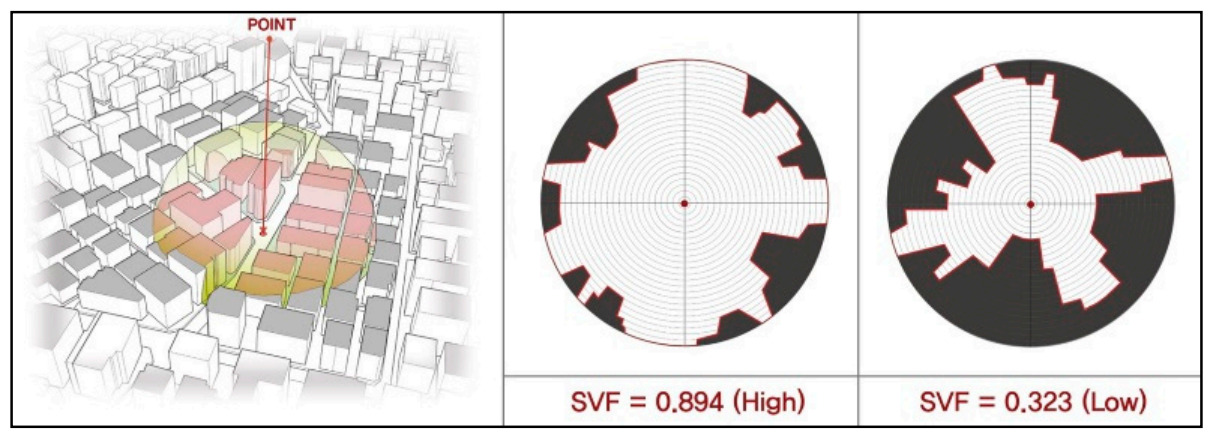

Figure 2. Examples of the Sky View Factor.

Urban ventilation paths, or wind corridors, have also been discussed in several previous studies, with respect to their positive effects in mitigating high temperatures [34-36]. To analyze and demonstrate urban wind environments, researchers have devised various parameters. A study by $\mathrm{Ng}$ et al. (2011) examined urban surface roughness by calculating the frontal area density across the study area in consideration of the prevailing wind direction [37]. Similarly, Gál \& Unger (2009) explored the influence of wind paths on thermal environments using urban surface roughness and porosity. Urban porosity was defined as the ratio of the open-air volume in the urban canopy layer (Figure 3); therefore, an urban environment with high porosity values indicates that more potential wind corridors exist, implying more desirable thermal environments in terms of human comfort [38].

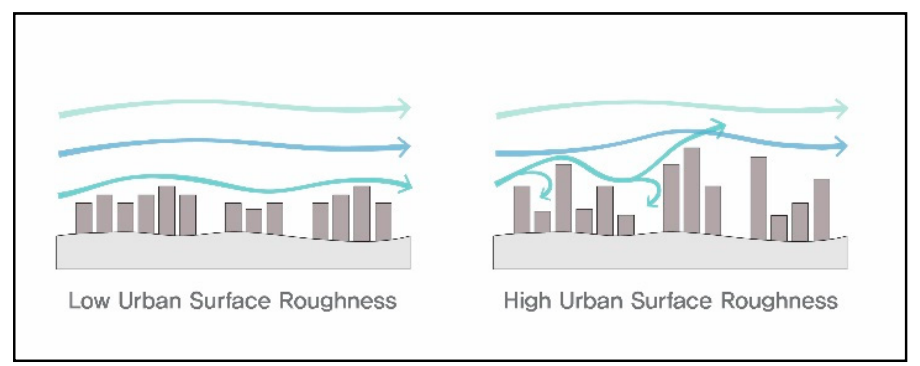

(a)

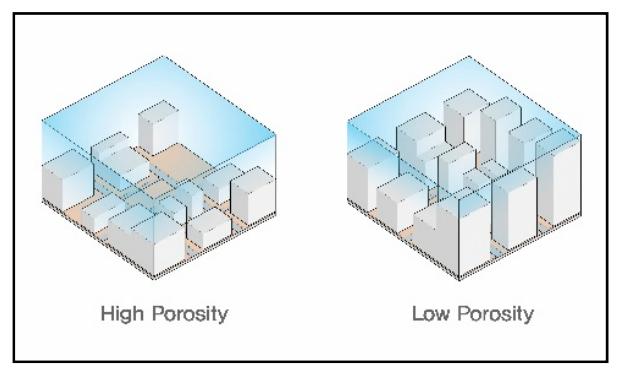

(b)

Figure 3. Illustrations of (a) urban surface roughness and (b) urban porosity.

\section{Methodology}

\subsection{Description of Study Areas}

Seoul $\left(37.3^{\circ} \mathrm{N}, 126.6^{\circ} \mathrm{E}\right)$, the capital city of the Republic of Korea, is one of the most densely built-up cities in the country, with a current size of $\sim 605 \mathrm{~km}^{2}$ and a population of nearly 10 million people (approximately $20 \%$ of the total population of the country). Various land use types are found in the city, ranging from small concentrations of industrial land-use purposes to residential areas, including three major central business districts (CBDs). Seoul has four distinctive seasons; each one lasts about three months. Summer in Seoul (June through August) is typically characterized as a hot and humid time of the year, because of the monsoon season. With global and urban warming effects, average air temperatures during summers in Seoul have been consistently rising and, moreover, the intensity and frequency of heat waves have become a serious problem throughout the city. 
The present study used climate data gathered from 217 AWSs around Seoul, which are operated by SK Weather Planet, the Seoul Metropolitan Government, and the Korean Meteorological Administration (Figure 4). The AWS consists of meteorological sensors and an enclosure containing the data-logger and a power supply. Each AWS is equipped with a thermometer, anemometer, wind vane, hygrometer, barometer and a rain gauge, and it records climate data automatically. The data include air temperature, relative humidity, wind speeds and directions, atmospheric pressure, and precipitation; these conditions were measured minute-by-minute during the study period (summer of 2015). To construct variables describing urban physical environments, units of analysis were defined as the region within a $500 \mathrm{~m}$ radius of each AWS. Thus, computed parameters within the buffer area were used to describe the built environment characteristics of each AWS.

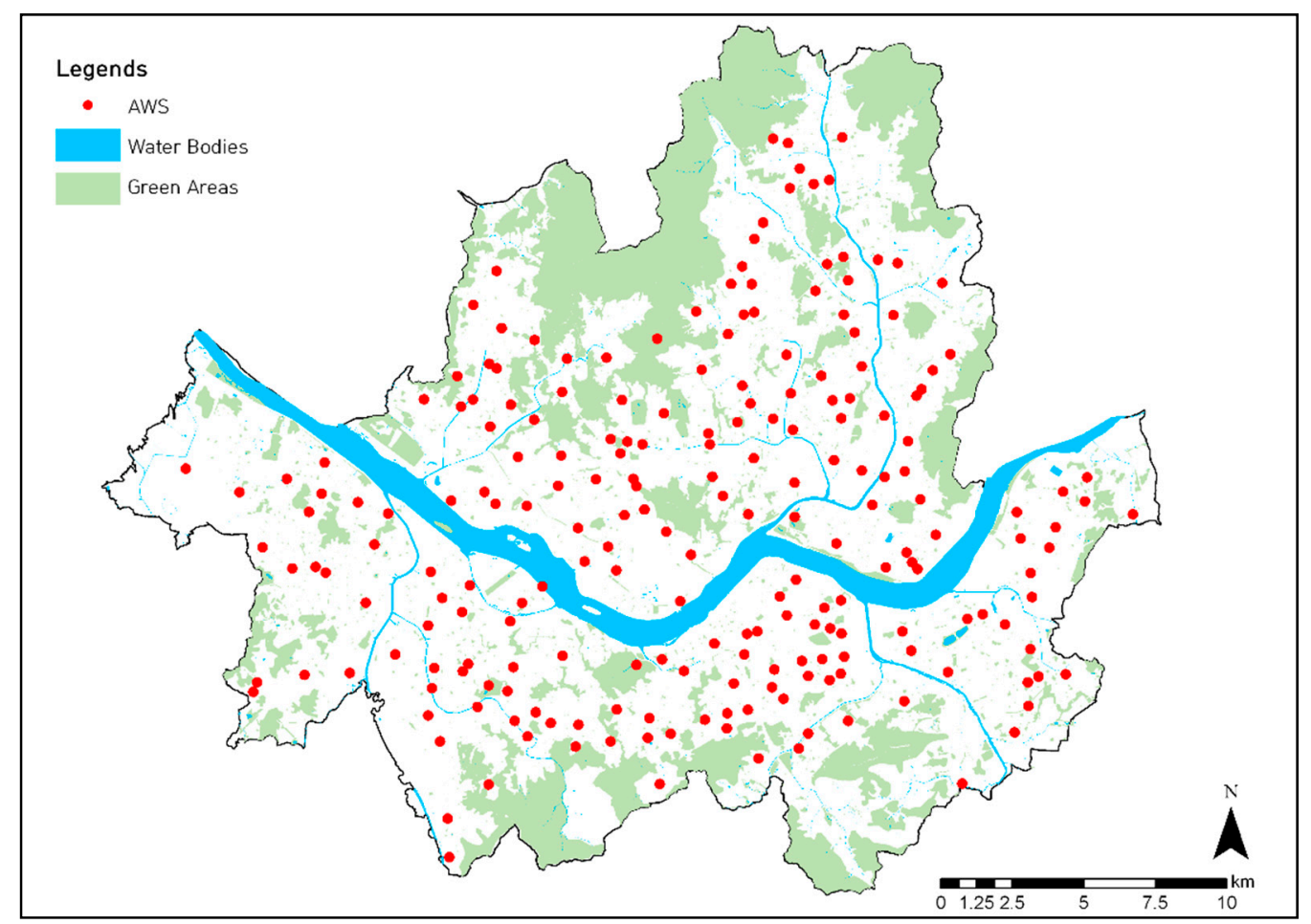

Figure 4. Locations of AWSs in Seoul.

\subsection{Variables}

\subsubsection{Climatic Parameters}

Since UHI effects in summer months have become a critical issue in Seoul, this research selectively explored urban thermal environments during the summer season (1 July-31 August 2015). We excluded climate data collected on rainy days and data with missing values; consequently, climatic parameters measured on only 49 days during the summer of 2015 were used to analyze thermal environments in the study areas.

The parameters that pertain to climate conditions consist of air temperatures, wind speeds, relative humidity, and solar radiation. Climatic variables measured from 09:00 to 18:00 were used in our analyses, in consideration of the characteristics of the durations of high air temperature, which mainly occur during the daytime. Durations of high air temperature, the dependent variable, were defined as days in which the air temperature is higher than $30^{\circ} \mathrm{C}$ (tropical days; maximum air temperature $\left(\mathrm{T}_{\max } \geq 30^{\circ} \mathrm{C}\right)$. Since climate data were collected at each AWS every minute during the study period, it was possible to calculate the durations of high air temperature at a detailed, minute-by-minute level. The rationale behind choosing the duration of high air temperature as a dependent variable to explain the intensity of UHI effects is that this parameter can intuitively demonstrate how long heated air 
lasts during daylight hours within a given urban canyon, which may deteriorate thermal comfort, leading to undesirable outdoor thermal environments for pedestrians.

As a detailed description of the dependent variable, Figure 5 shows the diurnal air temperature variations taken at two different AWSs (AWS1 and AWS2) on 1 August 2015. High air temperatures were measured from 09:59 to 20:29 at AWS 1; on the other hand, air temperatures exceeding $30^{\circ} \mathrm{C}$ were not observed at AWS2. Thus, the duration of high air temperature at AWS1 was $620 \mathrm{~min}$, and that at AWS2 was 0 min.

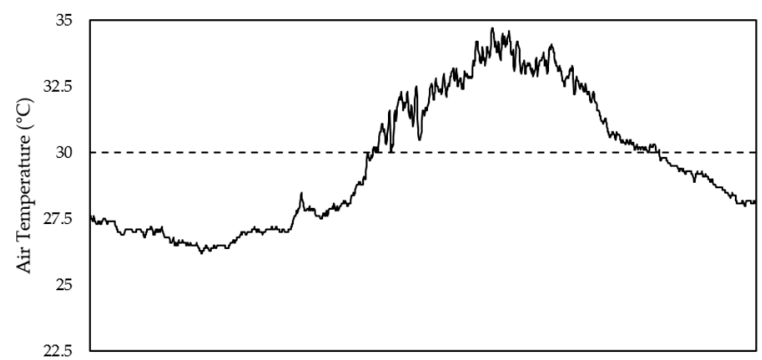

(a)

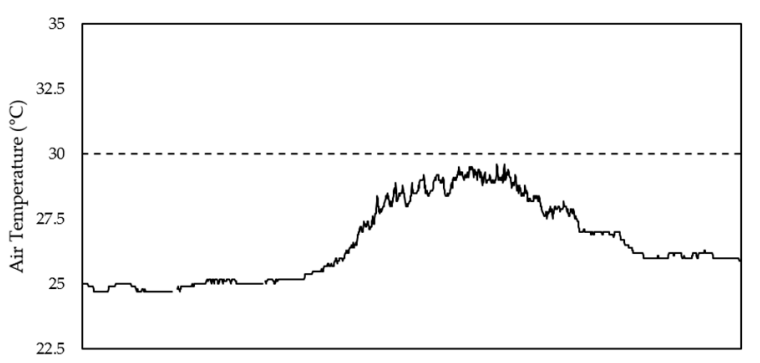

(b)

Figure 5. Diurnal air temperature variations (a) at AWS 1, where $620 \mathrm{~min}$ of high air temperature were measured; and (b) at AWS2, where durations of high air temperature were not observed.

\subsubsection{Parameters of Urban Physical Environments}

To compute the independent variables that determine urban physical environments, only urban elements within the study areas were used; study areas were demarcated by circles of $500 \mathrm{~m}$ radius centered on AWSs. Having reviewed previous studies, we selected several urban parameters, describing both urban surface characteristics and three-dimensional features within the urban canyon, to examine their effects on the durations of high air temperature.

Parameters for land surface features included road area, the distance to green space, distance from water bodies, and albedo values. The Gross Floor Area (GFA) of residential and commercial buildings, urban porosity, surface roughness, and the SVF were applied to demonstrate three-dimensional physical features.

The fraction of green space was calculated based on a thematic map of land cover classifications provided by the Environmental Geographic Information Service (EGIS) of the Korean Ministry of Environment. To compute the GFA of residential and commercial buildings, we used data offered by the Korean Ministry of Land, Infrastructure and Transport, which contains a diverse array of building information (e.g., building use types, floor area, building height, number of building floors, and other features). Additionally, albedo values of study areas were extracted from Landsat 8 satellite images.

A Digital Elevation Model (DEM) was obtained from the United States Geological Survey (USGS) and three-dimensional building information were combined in order to construct physical parameters within the urban canyon using ArcGIS. When calculating urban porosity, we adopted the method proposed by Gál \& Unger (2009), in which the height of an urban canyon $\left(h_{\max }\right)$ is defined as the maximum building height within a given study area [38]. The concept of urban porosity can be explained as the fraction of empty volume, subtracting building volumes $\left(V_{b l d}\right)$, from the total volume in the study area $(A)$. The total volume of an urban canyon will be the product of $h_{\max }$ and $A$, which equals to $A h_{\max }$. The equation used to determine urban porosity is as follows:

$$
\text { Urban Porosity }=\frac{A h_{\max }-\sum V_{b l d}}{A h_{\max }}
$$

Surface roughness was calculated by using the standard deviation of building heights and the surface elevation. We computed the SVF values for each cell of the DEM using software called Relief Visualization Toolbox and assigned the average value as the representative SVF value of the study area. 
After constructing all variables of interest, we carried out descriptive statistics in order to provide simple summaries of the samples (Table 1). The average value of the dependent variable, the duration of high air temperature, was 185.25 mins, with a standard deviation of 46.72 mins. In general, the GFA of residential buildings $\left(581,057 \mathrm{~m}^{2}\right)$ was greater than that of commercial buildings $\left(203,736 \mathrm{~m}^{2}\right)$. The land surface characteristic summaries for the study areas also revealed that road areas $\left(124,655 \mathrm{~m}^{2}\right)$ outweighed vegetated areas $\left(98,340 \mathrm{~m}^{2}\right)$, which indicates a high level of urbanization in Seoul. The results showed better accessibility to forests than to open water bodies, as the average distances to forest areas and to water bodies were 1,359 $\mathrm{m}$ and 3,731 $\mathrm{m}$, respectively. The average values for the urban porosity, surface roughness, and SVF parameters were $0.94,9.71 \mathrm{~m}$, and 0.59, respectively.

Table 1. Parameters describing both climate conditions and urban physical environments.

\begin{tabular}{|c|c|c|c|c|c|}
\hline \multicolumn{2}{|c|}{ Variables (obs. $=217$ ) } & \multirow{2}{*}{ Mean } & \multirow{2}{*}{ Std. dev. } & \multirow{2}{*}{ Min. } & \multirow{2}{*}{ Max. } \\
\hline Description & Unit & & & & \\
\hline Duration of high air temperature & $\min$ & 185.25 & 46.72 & 18.22 & 351.43 \\
\hline Wind speed & $\mathrm{m} / \mathrm{s}$ & 2.30 & 0.55 & 0.62 & 4.03 \\
\hline Relative humidity & $\%$ & 64.82 & 3.11 & 53.61 & 75.67 \\
\hline Solar radiation & $\mathrm{WH} / \mathrm{km}^{2}$ & 0.11 & 0.01 & 0.09 & 0.15 \\
\hline Elevation & $\mathrm{m}$ & 62.51 & 26.09 & 10.70 & 332.60 \\
\hline Residential gross floor area(GFA) & $\mathrm{m}^{2}$ & $581,057.10$ & $319,716.40$ & 202.42 & $2,037,215.00$ \\
\hline Commercial GFA & $\mathrm{m}^{2}$ & $203,735.90$ & $159,577.50$ & 0.00 & $802,740.80$ \\
\hline Road area & $\mathrm{m}^{2}$ & $124,655.20$ & $56,481.20$ & 122.37 & $572,619.90$ \\
\hline Vegetated area & $\mathrm{m}^{2}$ & $98,340.64$ & $116,781.60$ & 0.00 & $760,716.30$ \\
\hline Distance to forest areas & $\mathrm{m}$ & 1358.66 & 1153.52 & 0.00 & 4227.25 \\
\hline Distance from water bodies & $\mathrm{m}$ & 3730.90 & 2775.01 & 0.00 & $13,627.38$ \\
\hline Urban porosity & - & 0.94 & 0.02 & 0.85 & 1.00 \\
\hline Surface roughness & - & 9.71 & 4.26 & 0.14 & 21.81 \\
\hline Albedo value & - & 0.13 & 0.01 & 0.11 & 0.17 \\
\hline Sky view factor(SVF) & - & 0.59 & 0.10 & 0.42 & 0.99 \\
\hline
\end{tabular}

\subsection{Methods}

To examine the impacts of urban physical environments on the duration of high air temperature during the summer, we applied a multiple regression analysis and adopted an analysis unit of a $500 \mathrm{~m}$-buffer centered on each AWS. Moreover, the current research aimed to take a further step with respect to the effects of solar radiation trapping on thermal environments within urban canyons. A brief schematic of our approach for estimating solar radiation trapping effects is presented in Figure 6.

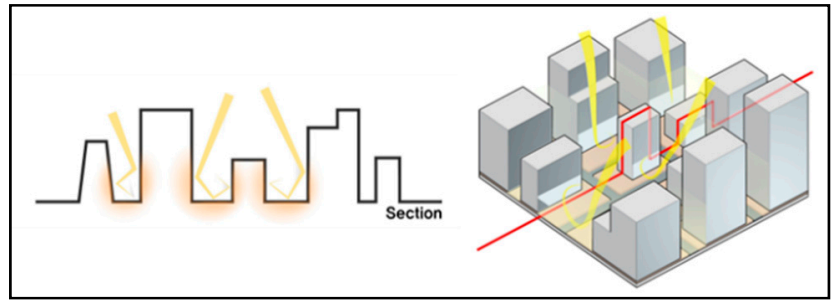

(a)

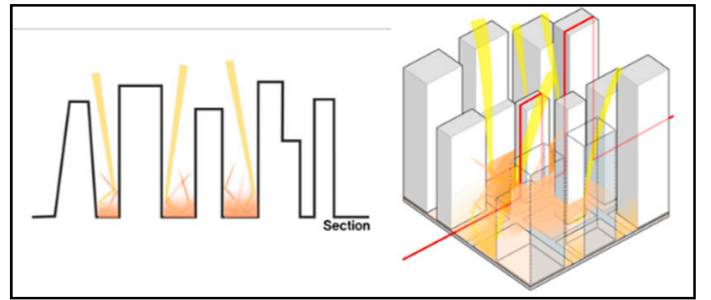

(b)

Figure 6. Illustrations of (a) weak solar radiation trapping effects within an urban canyon with low albedo values and a high SVF; (b) strong solar radiation trapping effects within an urban canyon with high albedo values and a low SVF.

While materials with high albedo values (e.g., light-colored pavements) are generally considered to help mitigate high air and surface temperatures, they can induce more radiation trapping and eventually worsen urban thermal environments. This is especially likely to occur in a street canyon with a low SVF, which refers to a closed outdoor space. Interaction effects between albedo values and SVFs were applied to our regression model to capture possible radiation trapping effects. 


\section{Results}

\subsection{Bivariate Analyses}

\subsubsection{Correlation Analysis}

To specify the relationships between the durations of high air temperature and urban physical environments, the Pearson correlation coefficient was used (Table 2). The results indicated that there were statistically significant correlations between the dependent variable and the parameters describing built environments.

Table 2. Results of the Pearson correlation test.

\begin{tabular}{cccc}
\hline & & The Duration of High Air Temperature \\
\hline \multirow{4}{*}{ Vlimate conditions and elevation } & Wind speed & -0.470 & $* * *$ \\
& Relative humidity & -0.552 & $* * *$ \\
& Solar radiation & -0.258 & $* * *$ \\
& Elevation & -0.282 & $* * *$ \\
\hline \multirow{4}{*}{ Urban physical characteristics } & Residential GFA & 0.196 & $* * *$ \\
& Commercial GFA & 0.289 & $* * *$ \\
& Road area & 0.157 & $* *$ \\
& Vegetated area & -0.166 & $* *$ \\
& Distance to forest areas & 0.202 & $* * *$ \\
& Distance from water bodies & -0.139 & $* *$ \\
& Urban porosity & -0.139 & $* *$ \\
& Surface roughness & 0.253 & $* * *$ \\
& Albedo values & -0.155 & $* *$ \\
& SVF & -0.314 & $* * *$ \\
\hline
\end{tabular}

Note: Sample size $=217 .{ }^{*} p<0.10 ;{ }^{* *} p<0.05 ;{ }^{* * *} p<0.01$.

The climatic parameters, including wind speeds, relative humidity, and solar radiation, had a strong negative correlation with the dependent variable. Based on the results, it was inferred that urban ventilation performance is a key factor in reducing durations of high air temperature and that the amount of incident solar radiation also plays an important role in that respect.

Among urban physical characteristics, the GFAs of both residential and commercial buildings showed positive coefficients, indicating that higher GFAs lead to longer durations of high air temperature. Similarly, the positive coefficient of road areas implied their negative impacts on outdoor thermal environments. Vegetated areas, on the other hand, had a negative correlation with the dependent variable. The reason behind this is that the evapotranspiration effects of vegetation help mitigate the duration of high air temperatures. The positive correlation between the distance to forest areas and the dependent variable is also associated with vegetation effects. There was a strong negative correlation between urban porosity and the duration of high air temperature. This result is reasonable, considering the role of urban porosity in improving ventilation performance within the canyon. Surface roughness, another parameter determining wind speeds and directions, showed a strong positive correlation with the dependent variable, in that greater values of surface roughness hamper effective wind ventilation. In accordance with results from previous studies, the albedo value and the duration of high air temperature were negatively correlated. The negative coefficient between the SVF and the dependent variable indicates that an urban area with higher SVF values, which is more open to the sky, has a more desirable street configuration in terms of comfortable thermal environments.

\subsubsection{Bivariate Regression Analysis}

The present study analyzed the impacts of physical parameters in urban built environments on outdoor thermal comfort in terms of the durations of high air temperature. In particular, we focused on solar radiation trapping effects. In order to specify the trapping effects, the interaction term between albedo values and SVFs was devised for use in the analysis model. The rationale behind this approach 
is that the positive effects of SVFs on thermal environments might vary depending on albedo values. This is because albedo values could negatively affect thermal environments within densely built-up areas by consistently reflecting incident radiation and causing the heated air to be trapped within the urban canyon, which is defined as solar radiation trapping effects. Our approach to estimating solar radiation effects was developed as follows: (1) We clustered 217 buffers based on their albedo values using the Jenks optimization method. (2) The difference in the impacts of SVFs on the dependent variable across different albedo groups was analyzed using the bivariate regression analysis.

The Jenks optimization method, a data classification method seeking to reduce the variance within classes and to maximize the variance between classes [39], was adopted to identify the breakpoints and to divide samples into two categories based on their albedo values (i.e., low albedo and high albedo groups). Consequently, 121 buffers were classified into the low albedo group and 96 buffers into the high albedo group, among 217 buffers with 500 m-radii.

The results of the bivariate regression analysis indicated that higher SVF values shortened the durations of high air temperature in both albedo groups, as shown in Table 3; however, based on the difference in regression coefficients, it was found that the positive effects of the SVF on the dependent variable were relatively diminished in the high albedo group compared to the low albedo group (Figure 7). This analysis, therefore, represents the fact that, even if an urban area is built with an optimal design plan in consideration of UHI effects (i.e., a high SVF and moderate building density), the mitigation effects of the SVF can dwindle in an urban canyon with high-albedo materials, due to solar radiation trapping effects.

Table 3. Results of bivariate regression analysis.

\begin{tabular}{cccc}
\hline \multirow{2}{*}{ Variables } & \multicolumn{3}{c}{ The Duration of High Air Temperature } \\
\cline { 2 - 4 } & \multicolumn{3}{c}{ Coef. } \\
\hline SVF & $\mathbf{9 5 \%}$ CI \\
\hline in the low albedo group & -215.3 & $* * *$ & $-303.5 \sim-127.1$ \\
in the high albedo group & -105.8 & $* * *$ & $-199.7 \sim-12.0$ \\
\hline
\end{tabular}

Note: Sample size in low albedo group $=121$; sample size in high albedo group $=96 .{ }^{*} p<0.10 ;{ }^{* *} p<0.05 ; * * * p<0.01$.

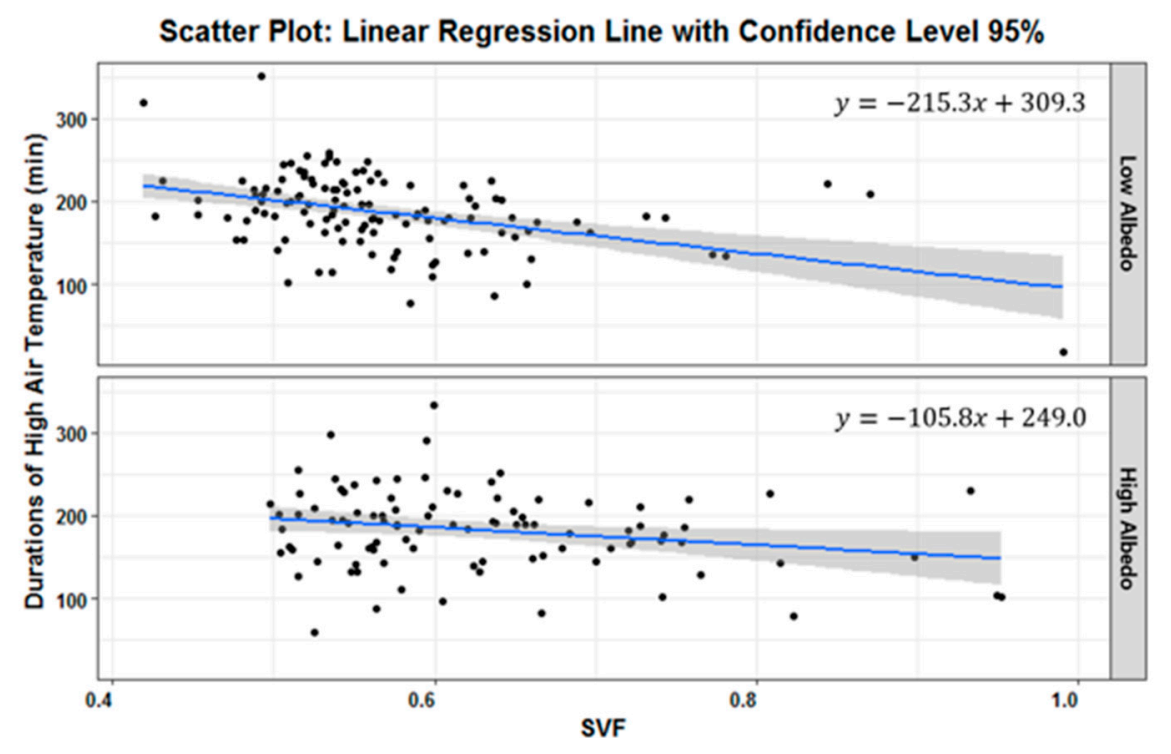

Figure 7. Scatter plots and linear fit of SVFs with durations of high air temperature.

Having performed bivariate analyses that provided simple and intuitive results, we found that there were statistically significant correlations between the durations of high air temperature and urban physical characteristics. Furthermore, the results of the bivariate regression analysis revealed possible 
radiation trapping effects. A bivariate model, however, has its inherent limitations, in that it cannot consider relationships among all the parameters of interest simultaneously. Thus, we took a further step to examine these relationships using a more advanced model, a multiple regression analysis.

\subsection{Multiple Regression Analysis}

To explore the relationships between variables in a more comprehensive manner, we implemented a multiple regression analysis with 14 independent variables focused on the interaction effects between SVFs and albedo values in order to detect possible radiation effects. The results are presented in Table 4 .

Table 4. Results of multiple regression analysis.

\begin{tabular}{|c|c|c|c|c|}
\hline & \multirow{2}{*}{ Variables } & \multicolumn{3}{|c|}{ The Duration of High Air Temperature } \\
\hline & & \multicolumn{2}{|c|}{ Coef. } & \multirow{2}{*}{$\frac{\mathbf{t}}{5.17}$} \\
\hline (Constant) & & 668.86 & $* * *$ & \\
\hline \multirow{4}{*}{$\begin{array}{l}\text { Climate conditions } \\
\text { and elevation }\end{array}$} & Wind speed & -38.74 & $* * *$ & -8.56 \\
\hline & Relative humidity & -4.44 & $* * *$ & -5.49 \\
\hline & Solar radiation & 1146.85 & * & 1.97 \\
\hline & Elevation & -24.72 & $* * *$ & -3.30 \\
\hline \multirow{10}{*}{$\begin{array}{l}\text { Neighborhood } \\
\text { physical } \\
\text { characteristics }\end{array}$} & Residential GFA & 0.01 & & 1.16 \\
\hline & Commercial GFA & 0.04 & $* *$ & 2.24 \\
\hline & Road area & 9.34 & $* *$ & 2.42 \\
\hline & Vegetated area & -0.55 & & -0.73 \\
\hline & Distance to forest areas & 2.26 & & 0.95 \\
\hline & Distance from water bodies & -1.31 & & -1.34 \\
\hline & Urban porosity & -201.62 & * & -1.73 \\
\hline & Surface roughness & 0.08 & & 0.10 \\
\hline & SVF & -137.89 & $* * *$ & -3.32 \\
\hline & $\begin{array}{l}\text { SVF X high albedo group } \\
\text { (radiation trapping effects) }\end{array}$ & 17.01 & * & 1.86 \\
\hline No. of obs. & & 217 & & \\
\hline $\mathrm{F}$ & & 18.87 & & \\
\hline Adjusted $\mathrm{R}^{2}$ & & 0.54 & & \\
\hline AIC & & 2131.70 & & \\
\hline $\mathrm{BIC}$ & & 2182.40 & & \\
\hline
\end{tabular}

Among climatic parameters, wind speeds and relative humidity showed negative coefficients; on the other hand, there was a positive relationship between solar radiation and the dependent variable. The results revealed that wind speeds have mitigating effects on the duration of high air temperatures. Thus, urban wind corridors can be used as an effective design strategy in terms of improving pedestrian thermal comfort during the daytime. In addition, the importance of shading effects in mitigating durations of high air temperature can be inferred from the positive coefficient of incident solar radiation.

While the relationship between the GFA of residential buildings and the dependent variable was not significant, the GFA of commercial buildings had a statistically significant correlation with the duration of high air temperature. Its positive coefficient indicated that a higher commercial GFA leads to longer durations of high air temperature. This result is reasonable, in that the parameters that contribute to anthropogenic sensible heat emissions (e.g., energy consumption, traffic volume, and the number of pedestrians) are relatively greater in commercial areas than in residential areas during the daytime, when high air temperatures are primarily measured. Similarly, road areas had a positive relationship with the dependent variable, implying that an urban area with more road areas will have longer durations of high air temperature. The rationale behind this result is that anthropogenic heat generated from traffic and road pavement materials (i.e., dark asphalt) with low albedo values and high heat capacities impede natural cooling. 
Additionally, we found that urban porosity, determined by the ratio of open-air volume within the canopy layer, contributed to effective urban ventilation performance by creating wind corridors. In accordance with previous studies, the results showed the mitigating effects of urban porosity on durations of high air temperature. Thus, the importance of ventilation paths should be taken into account when proposing urban designs so that durations of high air temperature can be shortened, and outdoor thermal comfort for citizens can be ameliorated.

The interaction term between SVFs and albedo values (clustered into high and low albedo groups) was considered in our analysis model in order to specify solar radiation effects. The results showed that an increase in the SVF contributed to shorter durations of high air temperature in both albedo groups, indicating that a built environment with a higher SVF, unobstructed by tall buildings, is a better urban configuration for improving thermal environments than an excessively dense urban area. In comparing the coefficient values between them, however, the SVF had a coefficient of -137.9 for the low albedo group, and a coefficient of $-120.9(=-137.9+17.0)$ for the high albedo group. These results revealed the effects of solar radiation trapping on the duration of high air temperature. In other words, even though higher SVFs helped to mitigate the durations of high air temperature in both albedo groups, the impacts of the SVF differed depending on the albedo values; higher albedo values diminished the positive effects of high SVFs, due to radiation trapping effects. Thus, the application of materials with an appropriate value should be discussed during the process of designing urban physical environments.

\section{Summary and Conclusions}

The present study used a multiple regression model to examine the impacts of urban physical environments on the durations of high air temperature during the summer season. Our approach for investigating possible solar radiation effects was to adopt an interaction term between SVFs and albedo values. In order to do so, we used detailed climate data gathered from 217 AWSs located around the Seoul area, and we empirically assessed the influences of parameters of interest on the duration of high air temperature.

The results indicated that high wind speeds lead to shorter durations of high air temperature, suggesting that urban ventilation plays a key role in improving thermal environments. Therefore, wind corridors should be considered an effective mitigation strategy to maximize urban ventilation performance. Additionally, more incident solar radiation induced longer durations of high air temperature, which seems reasonable, as solar radiation is the major factor increasing air temperature during the daytime. This result implies the importance of shading effects.

With regard to urban land-use characteristics, commercial GFAs had a negative impact on the dependent variable in this study. Higher GFAs in commercial buildings caused longer durations of high air temperature, possibly due to the great quantity of anthropogenic heat generated from high traffic volume, building energy consumption, and pedestrians. Therefore, mitigation strategies for commercial areas should be prioritized and addressed properly, since most citizens spend their time performing activities of daily living in commercial areas during the daytime.

Urban porosity, a parameter describing street canyon configurations, refers to the fraction of open-air volume within the canyon layer, and helps augment urban ventilation performance by creating more spaces for wind corridors. The results showed that high urban porosity positively influenced the duration of high air temperature, which is in accordance with earlier studies. Thus, urban designs should take into account the importance of urban porosity in order to increase ventilation effects and, eventually, ameliorate pedestrian thermal comfort in terms of durations of high air temperature.

Among parameters that pertain to land surface characteristics, it was found that an urban area with more road areas showed relatively longer durations of high air temperature compared to an urban area with fewer road areas. Considering road pavement characteristics (i.e., low albedo value and high heat storage capacity), a logical interpretation of the results is that roads impede effective natural cooling by emitting heat longer. In this regard, many city governments worldwide are considering 
cooling pavements with high albedo values as a design strategy to alleviate UHI effects. Despite these positive effects, reflective pavements should be applied in urbanized areas more cautiously, in a manner that suits the surrounding area. That is because reflective pavements may have unexpected drawbacks, known as radiation trapping effects, wherein they consistently reflect radiation within the urban canyon. This problem might be especially notable in densely built-up areas with low SVFs.

The interaction term between SVFs and albedo values was adopted for use in the current research to specify solar radiation trapping effects. More specifically, we examined whether the impact of the SVF on the duration of high air temperature varied depending on albedo values. The rationale behind this is that high albedo values would diminish the positive effects of the SVF on thermal environments if significant trapping effects are present. The SVF had a stronger positive impact on the duration of high air temperature in the low-albedo group than in the high-albedo group, which indicated that trapping effects were present. The major findings from the analysis of the interaction effects between SVFs and albedo values are as follows: (1) The SVF helped to mitigate the duration of high air temperature, in urban areas with both low and high albedo values. Therefore, urban planning decision-makers need to be cautious with the urban form with excessive building height and density in terms of thermal environments in cities, and design strategies to increase openness (i.e., to increase SVF values) can be effective tools for alleviating high air temperatures. (2) However, high albedo values diminished the positive effects of SVFs on the duration of high air temperature because of solar radiation trapping effects. These results indicate that materials with appropriate albedo values should be utilized, considering the fact that cooling pavements can impede the effective release of reflected radiation into the atmosphere.

Unlike previous research analyzing air or surface temperatures, the present study focused on the durations of high air temperature to depict the extent of UHI effects. Using a multiple regression model, the relationships between the durations of high air temperature and urban physical environments in the Seoul area were analyzed. Reviewing previous studies, we selected parameters affecting urban thermal environments and examined solar radiation trapping effects by adopting the interaction term between SVFs and albedo values. Our findings can potentially aid in UHI mitigation policies with respect to the duration of high air temperatures during the summer months. The current study, thus, complements previous research on the relationships between UHI effects and physical characteristics in urban areas. However, our study has limitations. We used climate data collected only from the summer of 2015 (1 July-31 August 2015); therefore, an analysis using multiannual data should be used in further investigations to provide more comprehensive results. Furthermore, future studies should address additional parameters describing urban physical environments, other than the variables assessed in the present study.

Author Contributions: Y.C., the leading author, initially conceived and designed the research. She performed data analysis and original draft preparation under the supervision of the corresponding author. S.L., a corresponding author, developed the original idea of this study and provided suggestions for the overall analysis. H.M., the third author, contributed to data collection and visualization. All authors contributed to manuscript preparation and discussed the results.

Acknowledgments: This research was supported by the Korea Agency for Infrastructure Technology Advancement (KAIA) grant (18AUDP-B102406-04) funded by the Ministry of Land, Infrastructure and Transport of the Korean Government. The part of this work was presented at the 2018 Spring Conference of the Urban Design Institute of Korea at the University of Seoul, Seoul, on 21 April [40].

Conflicts of Interest: The authors declare no conflict of interest.

\section{References}

1. Tan, J.; Zhen, Y.; Tang, X.; Guo, C.; Li, L.; Song, G.; Zhen, X.; Yuan, D.; Kalkstein, A.J.; Li, F.; Chen, H. The urban heat island and its impact on heat waves and human health in Shanghai. Int. J. Biometeorol. 2010, 54, 75-84. [CrossRef] [PubMed]

2. Dunne, J.P.; Stouffer, R.J.; John, J.G. Reductions in labour capacity from heat stress under climate warming. Nat. Clim. Chang. 2013, 3, 563-566. [CrossRef] 
3. Lee, S.; Bae, Y.S.; Shin, S.Y.; Kim, H.S. A Study on Strategy in Seoul Vulnerable to Extreme Weather; Seoul Development Institute: Seoul, Korea, 2010.

4. Smid, M.; Costa, A.C. Climate projections and downscaling techniques: a discussion for impact studies in urban systems. Int. J. Urban Sci. 2018, 22, 277-307. [CrossRef]

5. Wong, N.H.; Chen, Y.; Ong, C.L.; Sia, A. Investigation of thermal benefits of rooftop garden in the tropical environment. Build. Environ. 2003, 38, 261-270. [CrossRef]

6. Dimoudi, A.; Nikolopoulou, M. Vegetation in the urban environment: Microclimatic analysis and benefits. Energy Build. 2003, 35, 69-76. [CrossRef]

7. Susca, T.; Gaffin, S.R.; Dell'Osso, G.R. Positive effects of vegetation: Urban heat island and green roofs. Environ. Pollut. 2011, 159, 2119-2126. [CrossRef] [PubMed]

8. Millward, A.A.; Torchia, M.; Laursen, A.E.; Rothman, L.D. Vegetation placement for summer built surface temperature moderation in an urban microclimate. Environ. Manag. 2014, 53, 1043-1057. [CrossRef] [PubMed]

9. Skelhorn, C.; Lindley, S.; Levermore, G. The impact of vegetation types on air and surface temperatures in a temperate city: A fine scale assessment in Manchester, UK. Landsc. Urban Plan. 2014, 121, 129-140. [CrossRef]

10. Taleghani, M.; Tenpierik, M.; van den Dobbelsteen, A.; Sailor, D.J. Heat mitigation strategies in winter and summer: Field measurements in temperate climates. Build. Environ. 2014, 81, 309-319. [CrossRef]

11. Konarska, J.; Holmer, B.; Lindberg, F.; Thorsson, S. Influence of vegetation and building geometry on the spatial variations of air temperature and cooling rates in a high-latitude city. Int. J. Climatol. 2016, 36, 2379-2395. [CrossRef]

12. Sahana, M.; Dutta, S.; Sajjad, H. Assessing land transformation and its relation with land surface temperature in Mumbai city, India using geospatial techniques. Int. J. Urban Sci. 2018. [CrossRef]

13. Wang, Y.; Akbari, H. The effects of street tree planting on Urban Heat Island mitigation in Montreal. Sustain. Cities Soc. 2016, 27, 122-128. [CrossRef]

14. Hathway, E.A.; Sharples, S. The interaction of rivers and urban form in mitigating the Urban Heat Island effect: A UK case study. Build. Environ. 2012, 58, 14-22. [CrossRef]

15. Qiu, G.-Y.; Li, H.-Y.; Zhang, Q.-T.; Chen, W.; Liang, X.-J.; Li, X.-Z. Effects of Evapotranspiration on Mitigation of Urban Temperature by Vegetation and Urban Agriculture. J. Integr. Agric. 2013, 12, 1307-1315. [CrossRef]

16. Syafii, N.I.; Ichinose, M.; Kumakura, E.; Jusuf, S.K.; Chigusa, K.; Wong, N.H. Thermal environment assessment around bodies of water in urban canyons: A scale model study. Sustain. Cities Soc. 2017, 34, 79-89. [CrossRef]

17. Steeneveld, G.J.; Koopmans, S.; Heusinkveld, B.G.; Theeuwes, N.E. Refreshing the role of open water surfaces on mitigating the maximum urban heat island effect. Landsc. Urban Plan. 2014, 121, 92-96. [CrossRef]

18. Mackey, C.W.; Lee, X.; Smith, R.B. Remotely sensing the cooling effects of city scale efforts to reduce urban heat island. Build. Environ. 2012, 49, 348-358. [CrossRef]

19. Xiao, R.-B.; Ouyang, Z.-Y.; Zheng, H.; Li, W.-F.; Schienke, E.W.; Wang, X.-K. Spatial pattern of impervious surfaces and their impacts on land surface temperature in Beijing, China. J. Environ. Sci. 2007, 19, 250-256. [CrossRef]

20. Eliasson, I.; Svensson, M.K. Spatial air temperature variations and urban land use-A statistical approach. Meteorol. Appl. 2003, 10, 135-149. [CrossRef]

21. Hart, M.A.; Sailor, D.J. Quantifying the influence of land-use and surface characteristics on spatial variability in the urban heat island. Theor. Appl. Climatol. 2009, 95, 397-406. [CrossRef]

22. Oke, T.R. Street design and urban canopy layer climate. Energy Build. 1988, 11, 103-113. [CrossRef]

23. Bourbia, F.; Awbi, H.B. Building cluster and shading in urban canyon for hot dry climate Part 1: Air and surface temperature measurements. Renew. Energy 2004, 29, 249-262. [CrossRef]

24. Bourbia, F.; Boucheriba, F. Impact of street design on urban microclimate for semi arid climate (Constantine). Renew. Energy 2010, 35, 343-347. [CrossRef]

25. Krüger, E.L.; Minella, F.O.; Rasia, F. Impact of urban geometry on outdoor thermal comfort and air quality from field measurements in Curitiba, Brazil. Build. Environ. 2011, 46, 621-634. [CrossRef]

26. Fan, H.; Sailor, D.J. Modeling the impacts of anthropogenic heating on the urban climate of Philadelphia: A comparison of implementations in two PBL schemes. Atmos. Environ. 2005, 39, 73-84. [CrossRef]

27. Masson, V. Urban surface modeling and the meso-scale impact of cities. Theor. Appl. Climatol. 2006, 84, 35-45. [CrossRef] 
28. Hamdi, R.; Schayes, G. Sensitivity study of the urban heat island intensity to urban characteristics. Int. J. Clim. 2008, 28, 973-982. [CrossRef]

29. Martilli, A.; Clappier, A.; Rotach, M.W. An urban surface exchange parameterisation for mesoscale models. Boundary-Layer Meteorol. 2002, 104, 261-304. [CrossRef]

30. Ryu, Y.H.; Baik, J.J. Quantitative analysis of factors contributing to urban heat island intensity. J. Appl. Meteorol. Climatol. 2012, 51, 842-854. [CrossRef]

31. Gál, T.; Lindberg, F.; Unger, J. Computing continuous sky view factors using 3D urban raster and vector databases: Comparison and application to urban climate. Theor. Appl. Climatol. 2009, 95, 111-123. [CrossRef]

32. Yang, F.; Qian, F.; Lau, S.S.Y. Urban form and density as indicators for summertime outdoor ventilation potential: A case study on high-rise housing in Shanghai. Build. Environ. 2013, 70, 122-137. [CrossRef]

33. Ha, J.; Lee, S.; Park, C. The Temporal Effects of Environmental Characteristics on Urban Air Temperature: The Influence of Sky View Factor. Sustainability 2016, 8, 895. [CrossRef]

34. Georgakis, C.; Santamouris, M. Experimental investigation of air flow and temperature distribution in deep urban canyons for natural ventilation purposes. Energy Build. 2006, 38, 367-376. [CrossRef]

35. Niachou, K.; Livada, I.; Santamouris, M. Experimental study of temperature and airflow distribution inside an urban street canyon during hot summer weather conditions. Part II: Airflow analysis. Build. Environ. 2008, 43, 1393-1403. [CrossRef]

36. Memon, R.A.; Leung, D.Y.C.; Liu, C.H. Effects of building aspect ratio and wind speed on air temperatures in urban-like street canyons. Build. Environ. 2010, 45, 176-188. [CrossRef]

37. Ng, E.; Yuan, C.; Chen, L.; Ren, C.; Fung, J.C.H. Improving the wind environment in high-density cities by understanding urban morphology and surface roughness: A study in Hong Kong. Landsc. Urban Plan. 2011, 101, 59-74. [CrossRef]

38. Gál, T.; Unger, J. Detection of ventilation paths using high-resolution roughness parameter mapping in a large urban area. Build. Environ. 2009, 44, 198-206. [CrossRef]

39. Brewer, C.A.; Pickle, L. Evaluation of methods for classifying epidemiological data on choropleth maps in series. Ann. Assoc. Am. Geogr. 2002, 92, 662-681. [CrossRef]

40. Choi, Y.; Moon, H.; Lee, S. An analysis of the influence of neighborhood physical environment on durations of high air temperature: Focused on solar radiation trapping effects. In Proceedings of the 2018 Spring Conference of Urban Design Institute of Korea, Seoul, Korea, 21 April 2018. 